\title{
Psychiatry is warming up to personalized medicine 2.0
}

\author{
"...psychiatry once had a head start in the area of personalized \\ medicine, long before the term had even been invented."
}

First draft submitted: 15 December 2016; Accepted for publication: 3 February 2017; Published online: 3 May 2017

Keywords: Alice in Wonderland syndrome • catatonia • DSM-5 • network theory

During the era of classical psychiatry, doctors already suspected that heredity might well be the main driving force behind mental disorders. Today, with an estimated heritability of $46.3 \%$ for neuropsychiatric disorders in general [1], and of $70 \%$ for schizophrenia [2], the genomics era has proved those 19th century pioneers right, and instilled much optimism with regard to genetic tests enabling us to diagnose specific disorders, predict treatment responses to psychotropic substances and prevent side effects. And yet precisionhealth approaches are still rare in clinical psychiatry, with only few disorders - other than Huntington's disease and 22q11 deletion syndrome - lending themselves for genetic testing. With hundreds of causal genetic variants unearthed so far, and thousands suspected to exist, it is easy to blame this on the polygenic and pleiotropic nature of genetic contributions to psychiatric disease. And yet there is more. It is also due to the fact, as famously stated by Kenneth Kendler, that "patterns of underlying genetic liability do not map well onto current DSM [Diagnostic and Statistical Manual of Mental Disorders] categories - that is, our genes seem neither to have read DSM-IV nor to particularly respect the diagnostic boundaries it established" [3]. Since that insightful remark, the DSM has moved on to its fifth edition [4], but matching its numerous disorders with findings from genetic studies has remained an ongoing challenge, and the personalized approach has remained a rather futuristic ideal in psychiatry.

Which is a pity, since psychiatry once had a head start in the area of personalized medicine, long before the term had even been invented. Around the turn of the 19th century, the literature in my discipline brimmed with clinical descriptions, neuropathological findings and novel disease concepts that were readily applicable to individuals with highly specific symptoms and syndromes. I would have loved to be a doctor during that pivotal era, and browse through the freshly printed issues of scientific journals providing the exciting first descriptions of autoscopy [5], peduncular hallucinosis [6], Capgras' syndrome [7], Alzheimer's disease [8], dissociation [9], cryptomnesia [10], Riddoch's phenomenon [11] and many other symptoms, syndromes and disorders, only few of which eventually made it into the DSM. Given the phenomenal richness of that innovative period, we may ask ourselves - and should in fact ask ourselves - what happened during the intervening time to make us end up with diagnostic tools such as the DSM-5, which either lump those specific clinical disorders together into broad disease categories or fail to mention them at all.

The answer to that question is quite sobering. For lack of any specific therapeutic interventions, 19th century psychiatric

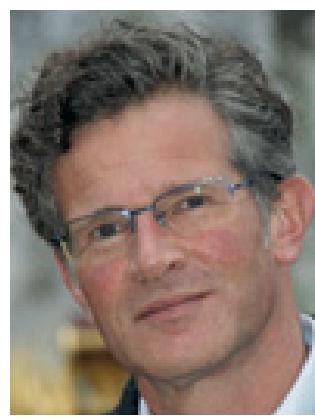

Jan Dirk Blom

Outpatient Clinic for Uncommon Psychiatric Syndromes, Parnassia Psychiatric Institute, The Hague, The Netherlands

and

Faculty of Social Sciences, Leiden University, Leiden, The Netherlands and

Department of Psychiatry, University of Groningen, Groningen, The Netherlands Tel.: +31 883570232 Fax: +31 883584195 jd.blom@parnassia.nl 
practice was more about managing the behavior of groups of inpatients than about establishing fancy diagnoses. The basic layout of asylums was 'men, unruly'/'women, unruly'/'men, quiet'/'women, quiet'. Therefore, the incentive to reflect on the sophisticated findings presented in contemporary scientific journals was low - which is quite understandable, as all one needed to know was whether admission was necessary, and whether the door should be locked or not [12]. That is how, in psychiatry, the first era of personalized medicine quietly died the death.

\section{"Missing the diagnosis means missing the opportunity to effectively treat some $90 \%$ of these patients.}

And all those lofty notions about heredity, what about them? They fell into the barren soil of the 19th century degeneration theory with its doctrine of 'damaged germ cells' that individuals supposedly acquired through illness, addiction and morally bad behavior, and passed on to their offspring, thus yielding an exponential weakening of subsequent generations, followed by extinction of the family line in give-or-take four generations [13]. The discovery of genes, chromosomes and DNA belonged to a distant future, and notions about heredity evoked doom scenarios rather than today's hopeful expectations.

In defense of our 19th century forebears, we should realize that the bulk of newly developed disease concepts had led to a sprawling nomenclature, which might have worked for specialists - provided that they kept up with the booming literature - but not for those in administrative functions, such as hospital directors, insurers and epidemiological statisticians. Medicine has always struggled to find a balance between seeing the bigger picture and the needs of the individual, and so, in reaction to this huge proliferation of disease concepts, the New York Academy of Medicine began campaigning for an overview of psychiatric disorders that would meet diagnostic as well as administrative needs. It took 25 years to realize that, but one day, in 1952, a spiral-bound booklet of 139 pages appeared, called the Diagnostic and Statistical Manual: Mental Disorders [14]. It contained an overview of psychiatric disease categories, mostly derived from classical textbooks of psychiatry that had served clinical purposes. In addition, it provided a nomenclature that was meant to be accepted nationally.

The first DSM was eventually followed by six revisions, each one more voluminous than its predecessor, with the most recent one (DSM-5, 2013) counting no less than 947 pages. Needless to say, the ring binder had in the meantime been dispensed of.
An important virtue of the DSM is that its diagnostic categories have a remarkably high reliability, and that the handbook has indeed succeeded in implementing a uniform nomenclature, not just in the USA, but worldwide. The prior abundance of disease terms has thus been effectively dealt with. However, the nosological gems they represented had now been equally effectively hidden from sight. As a consequence, there is now a yawning gap between the diagnoses psychiatrists are required to establish to see their patients reimbursed by insurance companies, and the specific disease concepts that they may believe applicable. The DSMs have often been criticized for including ever more diagnostic categories with each edition, as if psychiatry were out to pathologize ever more aspects of everyday life, but paradoxically, they offer far too few possibilities for establishing a proper diagnosis [15].

If I were allowed to submit a shortlist of clinical syndromes and disorders for the American Psychiatric Association to consider for inclusion in the forthcoming DSM, it would include at least catatonia (as a truly autonomous disease category), the incubus phenomenon, clinical zoanthropy [16], attention-deficit disorder psychosis [17] and a number of culture-bound syndromes that the DSM-5 mentions in passing, but which deserve to be developed into diagnostic categories in their own right. On top of that, I would wish for a new chapter on hallucinatory syndromes that would include, as separate categories, musical hallucinations, sexual hallucinations, peduncular hallucinosis and Charles Bonnet syndrome, as well as a new chapter called Alice in Wonderland syndrome, with an explicit listing of the 60 or so different types of metamorphopsia and other perceptual distortions that can be experienced in its context [18].

So far for my wish list. Those who might think that psychiatry will thus be trespassing shamelessly on the field of neurology are correct, because that is how we started out in the first place, and that is where our opportunities lie. After all, how else are we to book any progress in my field it is not by exploring brain functions to the full? Meanwhile there will remain plenty of room for us to take into account non-biological factors such as social anxiety, insomnia, occupational problems, relationship problems, social isolation and so on, which in the final analysis carry equally much weight in promoting psychiatric disorders as the biological ones. There is now an exciting new line of research, based on network theory, which makes it possible to describe the influence of such factors in scale-free, truly biopsychosocial models of disease, thus enabling us to transcend the traditional divide between mind, brain and environment [19].

The major reason why, after all, I am glad to be living and working in the 21st century, is that we now 
have the tools to investigate the neurobiological and neuropsychological underpinnings of the disease categories our predecessors around the fin de siècle so expertly described. Catatonia, for example, first conceived in its modern form by Kahlbaum in 1874, has been considered virtually extinct since the 1950s. And yet, today, it is found in some $15 \%$ of all patients in acute psychiatric nursing wards [20]. Missing the diagnosis means missing the opportunity to effectively treat some $90 \%$ of these patients. Because of this alone, catatonia deserves to be front and center in our classifications. What is more, recent studies indicate that at least some catatonic states are caused by NMDA receptor encephalitis, while others have started to unravel the genetic liability to catatonia in different subgroups.

The chances of finding any specific relations like these are much larger for specific clinical syndromes such as those described in the era of classical psychiatry, than for the container categories featured in the DSM, such as depressive disorder, anxiety disorder

\section{References}

1 Polderman TJC, Benyamin B, de Leeuw CA et al. Metaanalysis of the heritability of human traits based on fifty years of twin studies. Nat. Genet. 47(7), 702-709 (2015).

2 Gandal MJ, Leppa V, Won H, Parikshak NN, Geschwind $\mathrm{DH}$. The road to precision psychiatry: translating genetics into disease mechanisms. Nat. Neurosci. 19(11), 1397-1407 (2016).

3 Kendler KS. Advances in our understanding of genetic risk factors for autism spectrum disorders. Am. J. Psychiatry 167(11), 1291-1293 (2010).

4 American Psychiatric Association. Diagnostic and Statistical Manual of Mental Disorders (5th Edition). American Psychiatric Association, Washington, DC, USA (2013).

5 Féré $\mathrm{Ch}$. Note sur les hallucinations autoscopiques ou spéculaires et sur les hallucinations altruistes. Comptes Rendues Hebdomedaires des Séances et Mémoirs de la Société de la Biologie. 3, 451-453 (1891).

6 Lhermitte J. Syndrome de la calotte du pédoncule cérébral. Les troubles psycho-sensoriels dans les lésions du mésocéphale. Rev. Neurol. Paris 2, 1359-1365 (1922).

7 Capgras J, Reboul-Lachaux J. L'illusion des “sosies" dans un délire systematisé. Bulletin de la Société de Médecine Mentale 11, 6-16 (1923).

8 Alzheimer A. Über einen eigenartigen, schweren Erkrankungsprozess der Hirnrinde. Neurologisches Centralblatt 25, 1134 (1906).

9 Janet P. L'automatisme Psychologique. Essai de Psychologie Expérimentale sur les Formes Inférieures de l'Activité Humaine. Félix Alcan, Paris, France (1889).

10 Flournoy Th. Des Indes à la Planète Mars. Étude sur un Cas de Somnambulisme avec Glossolalie. Félix Alcan, Paris, France (1899). and schizophrenia. The other way around, it is to be expected that disease-causing genetic variants will soon inform our psychiatric classifications, and yield diagnostic categories hitherto undreamed of. So yes, as a clinical psychiatrist I am glad to be living and working in these exciting times, and I cannot wait to see my discipline combine the disease concepts of classical psychiatry with findings from genetic and other neurobiological research, thus ushering in the era of personalized medicine 2.0.

\section{Financial \& competing interests disclosure}

The author has no relevant affiliations or involvement with any organization or entity with a financial interest or financial conflict with the subject matter or materials discussed in the manuscript. This includes employment, consultancies, honoraria, stock ownership or options, expert testimony, grants or patents received or pending, or royalties.

No writing assistance was utilized in the production of this manuscript.
11 Riddoch G. Dissociation of visual perceptions due to occipital injuries, with especial reference to appreciation of movement. Brain 40, 15-57 (1917).

12 Chow WS, Priebe S. Understanding psychiatric institutionalization: a conceptual review. BMC Psychiatry 13(6), 169 (2013).

13 American Psychiatric Association. Diagnostic and Statistical Manual: Mental Disorders. American Psychiatric Association, Washington, DC, USA (1952).

14 Blom JD, van Praag HM. Schizophrenia: it's broken and it can't be fixed. A conceptual analysis at the centenary of Bleuler's Dementia praecox oder Gruppe der Schizophrenien. Isr. J. Psychiatry. Relat. Sci. 48(4), 240-248 (2011).

15 Shorter E. What Psychiatry Left Out of the DSM-5. Historical Mental Disorders Today. Routledge Taylor \& Francis Group, London, UK (2015).

16 Blom JD. When doctors cry wolf. A systematic review of the literature on clinical lycanthropy. Hist. Psychiatry 25(1), 87-102 (2014).

17 Blom JD, Niemantsverdriet MBA, Spuijbroek AT, Kooij JJS. Attention deficit disorder psychosis. In: Unusual and Rare Psychological Disorders. A Handbook for Clinical Practice and Research. Sharpless BA (Ed.). Oxford University Press, Oxford, UK, 74-93 (2017).

18 Blom JD. Alice in Wonderland syndrome: a systematic review. Neurol. Clin. Pract. 6(3), 1-12 (2016).

19 Looijestijn J, Blom JD, Aleman A, Hoek HW, Goekoop R. An integrated network model of psychotic symptoms. Neurosci. Biobehav. Rev. 59(12), 238-250 (2015).

20 Stuivenga M, Morrens M. Prevalence of the catatonic syndrome in an acute inpatient sample. Front. Psychiatry 5(12), 174 (2014). 